\title{
Comment
}

\section{Science centres around the world see unrest for art and science in society}

\begin{abstract}
Alessandra Drioli
ABSTRACT: In present times it would not be appropriate to say art made a "debut" in science centres, as it has been a feature since the beginning of their history, and it appeared precisely in the 'parent' science centre, the Exploratorium. However, now it is time to check the progress. There is unrest for this issue, as in history-making times, and it is worthwhile to follow the new developments and hear the words of the coordinators of the artistic activities in science centres and, more in general, in science museums, and also of the artists involved in the process. The goal is to promote a debate on the final results of this phenomenon and on what will happen next. Also, emphasis should be put on the importance for each museum to define right from the start an 'art policy', even a complex one, but somehow structured, that may be employed at many levels according to the needs of the museum itself.
\end{abstract}

In the late sixties Frank Oppenheimer, founder of Exploratorium of San Francisco, the first science centre in the world, said: "Art is included, not just to make things pretty, although it often does so, but primarily because artists make different kinds of discoveries about nature than do physicists or geologists. The purpose of science and art is to understand nature with the involvement of people. And as they mix, they become part of the pedagogical process."

Therefore, in present times it would not be appropriate to say art made a "debut" in science centres, as it has been a feature since the beginning of their history, and it appeared precisely in the 'parent' science centre, the Exploratorium. The way this occurred and the museums that have followed the same path were the subjects of an article of mine published in this journal (see the article in JCOM no. 5 of 2006). Now I will go back to this because there is unrest again for the issue, as in history-making times, and it is worthwhile to follow the new developments and hear the words of those coordinating the artistic activities in science centres and, more in general, in science museums, and also of the artists involved in the process. The goal is to promote a debate on the final results of this phenomenon and on what will happen next. Also, emphasis should be put on the importance for each museum to define right from the start an 'art policy', even a complex one, but somehow structured, that may be employed at many levels according to the needs of the museum itself. This way it is also possible to better communicate the value and the importance art has in each museum, streamlining investments and not wasting efforts in many activities that cannot be received at best by the public. This is also to avoid the risk of reducing art to a 'fashionable ingredient' not adding or removing anything.

After this preliminary remark, it should be immediately clarified that we are facing quite a complex picture. Some museums, as previously reported, have long followed this path, but now they are wondering how to go on. This is the case of the Exploratorium, which has prepared a report entitled "A vision of art at the Exploratorium. A plan for programmes, research, and the creation of new work, 20072012". This report focuses on the pivotal elements which, according to the museum working group that wrote it, are necessary to set up an organic artistic action. Some other museums, although having old origins and a more traditional approach, have recently been exploring new communication channels including art. An example of this (incidentally one of the experiences featured in this commentary) is the Natural History Museum of London which - after some important temporary exhibitions and installations between 2006 and 2007 which saw the involvement of various artists - inaugurated its first permanent art installation this year, Tania Kovats' 'TREE'. And yet, the most interesting data apparently emerging from the words of Bergit Arends, curator of Contemporary Arts at the Natural History Museum 
since September 2005, is the identification of a consistent and continuative artistic programme integrating with the other activities of the museum and, in more general terms, with its mission. Claudio Giorgione is the curator of the Dipartimento Leonardo Arte \& Scienza of the Museum of Science and Technology "Leonardo da Vinci" of Milan (even the name of the museum itself claims there is a close link between art and science by imprint) and also his words confirm this: there is a role played by art, both ancient and contemporary, which permeates the museum. First, since 1953 as an instrument through which the Museum created breathtaking installations and now, ever more frequently, as an occasion to encourage the debate and the discussion in the public. A very interesting case is also the Science Museum of London: Hannah Redler, manager of the "Arts Projects" told us the experiences implemented since 1996 to reconstruct the complex path that led the Science Museum to choose art as a form of representation of the impact of science on the everyday life of citizens.

Quite importantly indeed, each museum should support an artistic programme, even a long-term one, which should guarantee continuity and consistency. Each science centre should also identify the human resources with the right expertise and skills to follow the development of such a programme. Only with such an approach can art play a significant role in science museums. And in this context a reference can be made to another category of museums, those founded only recently, but which immediately made art and design a leading theme of theirs. An example of this is the Science Gallery of Dublin that, despite its young age, approximately one year, can already boast a respected curriculum and a strong and enterprising identity. After a series of exhibitions devoted to light, pills and robotics, it has just inaugurated "Infectious: stay away". Among overalls and protective masks, multimedia and interactive installations, this exhibition explores not only the dynamics of infections, from everyday life ones to the rarest and most dangerous ones, but also how ideas, cultures, etc. become infectious. In short, "infectious" in every possible way, precisely in a time when the swine flu puts all of us in a state of alert. To organize this event, as well as the previous ones, an open call for ideas was launched and addressed to scientists, engineers, artists, designers and creative thinkers to gather ideas, projects and works. And while the Science Gallery is now welcoming a large number of people willing to visit the exhibition, the call for ideas for the next event is already online and it reads: "The Science Gallery at Trinity College Dublin is seeking ideas and proposals for a new interdisciplinary exhibition and festival exploring nanotechnology and its implications for our future. Focussed on the dreams, nightmares, possibilities and achievements of this broadly interdisciplinary field, the exhibition will explore what it means to act in a realm we can never directly see and to consider how our emerging science and technology is enmeshed with some of our deepest hopes and fears. So Science Gallery wants your suggestions and ideas for events, speakers, debates, films, workshops, live experiments performances, competitions, exhibits, interactive installations and demonstrations exploring nanotechnology, its applications and implications". Therefore, also this formula appears to be viable and presently able to yield positive results. Science Gallery is indeed able to move fast and in a dynamic way along the paths of a dialogue between science and society which is modern, young and across frontiers.

Evidently all of this is possible because in the artistic community people feel an equally strong need to reflect and to express themselves on scientific issues. The stories of the Slovenian collective Brida, of the American artist Susie Lee and of the Cooperativa di Teatro Le Nuvole are extremely significant. All of them, with different methods and experiences, have interfaced with the most modern and pressing scientific issues in the science-society dialogue, from nanotechnologies to biotechnologies, sustainable development, climate change, etc., stimulating new forms of confrontation and debate. This is because art can be a sort of antenna, a testing agent for what is happening in science and society, precisely what our science museums need and are searching for today. Science centres, as well as many science museums, actually behave as key players in social changes, managing to spread within themselves a multitude of figures and competences. Thus, artists and scientists can collaborate, clash, question one another on so many different issues, from the foundations of our knowledge to the most topical ones. Now they have someone to offer them a space to provide the public with the results of their work or else the work in progress of their research.

Translatex by Massimo Caregnato 


\section{Author}

Alessandra Drioli is an art historian and a museologist. Since 1997, she works at the Science Centre of Città della Scienza of Naples, where she has played many roles such as Manager of the Exhibition Areas and of the Special Projects, specializing in exhibition events planning and implementation. Now she coordinates the activities of art and science of the museum. Recently she published the book Vietato non toccare ('Not Touching is Not Allowed') devoted to the role played by art in science museums.

E-mail: drioli@cittadellascienza.it.

How TO CITE: A. Drioli, Science centres around the world see unrest for art and science in society, Jcom 08(02) (2009) C01 